\title{
An aggressive, novel approach using a vacuum-assisted system to treat thoracic aortic graft infection
}

\author{
Karen M. Kim, MD, and Wilson Y. Szeto, MD
}

\footnotetext{
From the Division of Cardiovascular Surgery, Department of Surgery, University of Pennsylvania Medical Center, Philadelphia, Pa.

Disclosures: Authors have nothing to disclose with regard to commercial support.

Received for publication June 23, 2015; accepted for publication June 23, 2015; available ahead of print July 22, 2015.

Address for reprints: Wilson Y. Szeto, MD, Division of Cardiovascular Surgery, University of Pennsylvania Medical Center, Penn Presbyterian Medical Center, 51 N 39th St, Heart \& Vascular Pavilion 2A, Philadelphia, PA 19104 (E-mail: wilson.szeto@uphs.upenn.edu).

J Thorac Cardiovasc Surg 2015;150:e39-40

$0022-5223 / \$ 36.00$

Copyright $(2015$ by The American Association for Thoracic Surgery

http://dx.doi.org/10.1016/j.jtcvs.2015.06.057
}

In this small series, Hosoyama and colleagues ${ }^{1}$ have described their use of negative pressure wound therapy and delayed sternal closure after resection and replacement of infected ascending aortic grafts to decrease the risk of recurrent infection. They performed daily dressing changes at the intensive care unit (ICU) bedside for 9 days, without hemorrhagic complications. All 4 patients survived, with follow-up ranging from 1 to 5 years. For 1 patient, they were even able to eradicate Candida infection, a difficult organism to treat in the mediastinum.

The mortality from ascending aortic graft infection can be as high as $35 \%$. Approaches to this difficult problem have led to variable success in treating the infection without significant morbidity and mortality, and more importantly, preventing recurrent infection. Antibiotic therapy alone is rarely successful without other measures to debride infected tissue. Mediastinal debridement without graft resection, followed by coverage with an omental or muscle flap, avoids the morbidity of graft replacement, but patients may need to continue lifelong, suppression antibiotic therapy for the remaining graft itself. Replacing infected Dacron graft with new Dacron or homograft may be more effective, but this is a fairly major operation, especially in older patients with multiple comorbidities, complications from sepsis, and decreased nutritional reserve. This group's approach, of performing graft resection and replacement, using omental coverage, leaving the chest open, performing daily dressing changes in the ICU until cultures cleared, and delaying sternal closure, was aggressive but successful. The materials used are available in any hospital, and although the process is labor intensive, performing dressing changes in the ICU obviates the need for daily transport to the operating room and the use of operating room time.

One would think that the possible bleeding complications of using negative pressure wound therapy directly on aortic graft, as well as in the setting of postcardiopulmonary bypass coagulopathy, would contraindicate its use. infection.

\section{References}

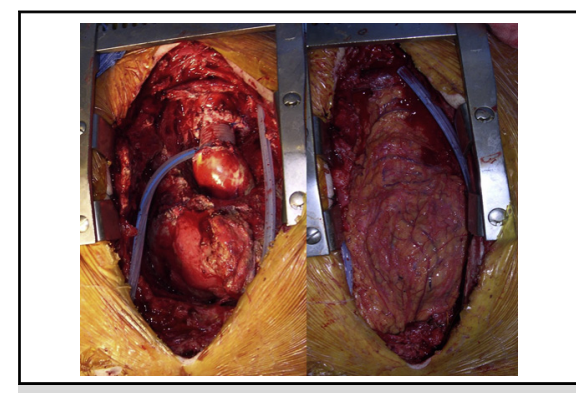

Infected root and ascending graft replaced with homograft and graft; interval omental flap.

\section{Central Message}

This aggressive approach for thoracic aortic graft infection should be considered to improve the chances of clearance and recurrence.

See Article page e36.

Petzina and colleagues, ${ }^{2}$ in their retrospective review of 69 patients with postcardiotomy mediastinitis treated with negative pressure wound therapy, reported that $7.2 \%$ of patients had serious bleeding complications. Hosoyama and colleagues ${ }^{1}$ did not find this to be the case, but their series is very small. The use of paraffin gauze layers or a rigid barrier has been suggested as a way to protect the heart and great vessels from negative pressure-related trauma. ${ }^{3}$ An encouraging development is that vascular surgeons have used negative pressure wound therapy in deep perivascular wound infections in the groin, resulting in significantly faster healing compared with traditional wound treatments, and a low incidence of bleeding complications. This improvement may be facilitated by use of lower continuous negative pressure $(50-75 \mathrm{~mm} \mathrm{Hg})$, rather than the more commonly used $125 \mathrm{~mm} \mathrm{Hg}$.

At our institution, although we are more familiar with graft resection and replacement, omental or tissue flap placement in the mediastinum, and immediate chest closure, perhaps this aggressive approach should be considered in the setting of extensive mediastinal infection, or a particularly difficult organism (ie, gram-negative rods, fungus), to help improve the chances of clearance and to prevent recurrence of graft

1. Hosoyama K, Kawamoto S, Motoyoshi N, Saiki Y. Intraoperative vacuum-assisted closure following in situ graft replacement for and infected thoracic aortic graft. J Thorac Cardiovasc Surg. 2015;150:e36-8. 
2. Petzina R, Malmsjö M, Stamm C, Hetzer R. Major complications during negative pressure wound therapy in poststernotomy mediastinitis after cardiac surgery. $J$ Thorac Cardiovasc Surg. 2010;140:1133-6.

3. Ingemansson R, Malmsjö M, Lindstedt S. A protective device for negativepressure therapy in patients with mediastinitis. Ann Thorac Surg. 2013;95:362-4.
4. Berger P, de Bie D, Moll FL, de Borst GJ. Negative pressure wound therapy on exposed prosthetic vascular grafts in the groin. J Vasc Surg. 2012;56:714-20.

5. Monsen C, Wann-Hansson C, Wictorsson C, Acosta S. Vacuum-assisted wound closure versus alginate for the treatment of deep perivascular wound infections in the groin after vascular surgery. J Vasc Surg. 2014;59:145-51. 